\title{
Strategies for Transformation and Quality Growth
}

The United Nations plan of action, Transforming Our World: The 2030 Agenda for Sustainable Development, ${ }^{1}$ states at its beginning, "We envisage a world in which every country enjoys sustained, inclusive and sustainable economic growth and decent work for all" (United Nations 2015, 4). The emphasis on the desired attributes of economic growth expressed in this vision of the Sustainable Development Goals (SDGs) coincides with the recent growth in attention toward the concept of quality growth. In the Asia-Pacific region, Asia Pacific Economic Cooperation (APEC) leaders agreed on an "APEC Growth Strategy" in 2010, which stressed that the quality of growth needs to be improved to ensure that it will be more balanced, inclusive, sustainable, innovative, and secure (APEC 2010). ${ }^{2}$ APEC leaders further agreed on the "APEC Strategy for Strengthening Quality Growth" in 2015, which "will bring more synergy between the APEC Growth Strategy and the Sustainable Development Goals" (APEC 2015, 1). The "Development Cooperation Charter of Japan," also released in 2015, states that one of the most important challenges for development is "quality growth" and "poverty reduction through such growth," in which inclusiveness, sustainability, and resilience are stressed (Cabinet Office 2015, 5-6).

Along with this emphasis on quality, increasing attention is being paid to the importance of transformation, considered essential for development. As the Asian Development Bank
(ADB) asserted, development is distinct from aggregate growth, which can occur without significant transformation, as in some oil rich economies (ADB 2013).

In this chapter, I provide insights on strategies to attain transformation with quality growth, along with effective approaches for implementing them. First, I present an overview of recent policy debates related to transformation and quality growth. On the basis of this discussion, I provide an analytical perspective and discuss key issues, identifying seven main strategies: three to address endowments and four to catalyze transformation. In subsequent sections, I discuss each specific strategy, drawing insights from relevant effective approaches. In the final section, I offer concluding remarks.

\subsection{Key Issues from an Analytical Perspective}

\subsubsection{Overview of Transformation and Quality of Growth in East Asia, Latin America, and Africa}

The Report of the High-Level Panel of Eminent Persons on the Post-2015 Development Agenda, "A Global Partnership: Eradicate Poverty and Transform Economies through Sustainable 
Development" (High-Level Panel 2013), concluded that the post-2015 agenda needs to be driven by five transformational shifts, including a call for the transformation of economies for jobs and inclusive growth. The United Nations 2030 Agenda declares that "we are determined to take the bold and transformative steps which are urgently needed to shift the world on to a sustainable and resilient path" (United Nations 2015, 2).

Thus, these governing bodies seem to have reached more of a consensus on the importance of quality of growth on the one hand, and transformation on the other. This consensus is reflected in the recent publications of regional institutions pertaining to their region, including the Asian Development Bank (ADB), UN Economic and Social Commission for Asia and the Pacific (UNESCAP), Inter-American Development Bank (IDB), UN Economic Commission for Latin America and the Caribbean (UNECLAC), African Development Bank (AfDB), African Union, UN Economic Commission for Africa (UNECA), and the African Centre for Economic Transformation (ACET). ${ }^{3}$ In this section, after elaborating on this trend in Africa, I will discuss the relationship between "quality of growth" and "transformation" (see Further Discussion 2.1)

In the African region, heads of state and governments endorsed the African Union's transformation vision for 2063. The AfDB's long-term strategy, "At the Center of Africa's Transformation," has the goal of establishing Africa as the next global emerging market. Moreover, UNECA's Economic Report on Africa 2013 details what will be required to promote competitiveness, reduce dependence on primary commodity exports, and enable Africa to emerge as a new global growth pole. Therefore, as ACET states, economic transformation is now the consensus paradigm for Africa's development. ACET's flagship report, 2014 African Transformation Report: Growth with Depth, is considered to be the pioneering comprehensive study on transformation of the African economy. ${ }^{4}$

Behind the recent tendency in each of these three regions to emphasize transformation and quality of growth are concerns that growth does not necessarily enable development when it is not accompanied by transformation or by the attributes of the quality of growth. ACET's 2014 African Transformation Report agrees that, to "ensure that growth is sustainable and continues to improve the lives of many, countries need to vigorously promote economic transformation" (ACET 2014, 1). In short, quality growth needs to be discussed in the context of transformation because it is both a driver of growth ${ }^{5}$ and affects different attributes of growth.

\subsubsection{Transformation and Changing Endowments}

This section summarizes the basic aspects of economic, industrial, and structural transformation on which there has been growing consensus in recent years. First, regarding the definition of transformation, a well-established body of literature affirms that development is about transforming the productive structure of the economy and accumulating the capabilities necessary to undertake this process (ADB 2013). This process can be best described by ACET's concept of growth with depth. On the basis of various studies, I identify four strategies for transformation.

Second, regarding how transformation can be achieved, consensus seems to be growing that structural transformation is closely related to changes of endowments or assets and changes in comparative advantage as well as to innovation and technological progress (e.g., see Noman and Stiglitz 2012; see also Lin 2012a).

Accordingly, endowments are extremely important for transformation based on changing or dynamic comparative advantage. In this regard, recent studies identified critical endowments for transformation. Along with the growing recognition of the importance of inclusiveness and innovation in quality growth, discussions on the importance of learning, as well as the accumulation of knowledge and capabilities, have deepened.

Stiglitz and Greenwald (2014) present a systematic and holistic analysis of what constitutes a 
learning society, arguing that "the most important 'endowment' from our perspective, is a society's learning capacities" (26). They further state that a country's policies have to be shaped to take advantage of its comparative advantage in knowledge and learning abilities in relation to its competitors, including its ability to learn and to learn to learn, and to support those capacities and capabilities further. Noman and Stiglitz (2017) reaffirm the importance of learning capacity, together with that of institutions: "Perhaps the most important 'endowment' of a country was assets that were not mobile - institutions and learning capacities that were embedded in local institutions. It was these that countries needed to take into account as they struggled to shape their long-term (dynamic) comparative advantage" (13).

Another important endowment could be infrastructure, both hard and soft. Lin (2012b) states that "economic development is a dynamic process that requires industrial upgrading and diversification along with corresponding improvements in 'hard' and 'soft' infrastructure at each new level." He further argues that "Such upgrading entails large externalities to firm transaction costs and the returns to capital investment. Therefore, in addition to an effective market mechanism, the government should coordinate or provide the improvements in infrastructure and compensate for the externalities to facilitate industrial upgrading and diversification" (10). Hard infrastructure consists of highways, telecommunications networks, port facilities, and power supplies, while soft infrastructure is made up of institutions, regulations, social capital, value systems, and other social and economic arrangements.

These endowments - namely, learning capacities (as defined by Stiglitz and Greenwald), infrastructure, and institutions (including other soft infrastructure as discussed by Lin) - are not mobile. These three essential endowments, along with standard factor endowments such as labor, land, and capital, ${ }^{6}$ are critical for the dynamic comparative advantage of a country.

These three essential endowments bear a close relation to the elements Japan's Development Cooperation Charter considers important: "Japan will attach importance to building the foundations of self-help efforts and self-reliant development such as human resources, socioeconomic infrastructure, regulations and institutions" (Cabinet Office 2015, 5). ${ }^{7}$ This view has been incorporated into Japan's Official Development Assistance policies for decades (Ministry of Foreign Affairs [MOFA] 2005). ${ }^{8}$

It is worth mentioning that Japan's ODA policy emphasis on "human resources" has a close relationship with its emphasis on the importance of "learning" and "learning capacity." As Kato, senior vice-president of Japan International Cooperation Agency (JICA), states, "Another characteristic of Japan's ODA is its very strongalmost "obsessive"-emphasis on human resource development. Human resource development is an absolute priority unanimously upheld by those working in development. It is a kind of 'collective wisdom' shared among Japanese society. ... In practical terms, 'human resource development', means two things: one is the belief in the vital importance of formal education... the other meaning of human resource development for Japan's development practitioners, which perhaps sets Japan apart from other donors, is the importance placed on nurturing people's practical problem solving capacity (emphasis in original). This includes many things: to be disciplined at work, be able to identify and solve problems using available resources and knowledge, to have an attitude to try to improve things gradually (kaizen) rather than expecting drastic changes, and to work collaboratively with people" (Kato 2016, 11) (For these aspects of Japanese approach, including Kaizen, see Chap. 4). Similarly, as discussed in the Section on "Strategy for investing in quality infrastructure" later in this chapter, the emphasis on infrastructure in Japan's ODA is well known.

Thus, from the lens of quality growth through transformation, the three essential endowmentslearning capacity, infrastructure, and institutions, among others - need to be enhanced, taking into account inclusiveness, sustainability, and resilience. From this, I can derive three strategies to enhance each of the essential endowments necessary for transformation for quality of growth. The other challenge lies in finding ways to 
catalyze transformation for quality growth. To address this challenge, I identify four additional strategies.

Transformation agendas differ among countries, such as countries with a very high proportion of the population living in rural areas, early industrializing countries, urbanizing countries, and countries that need to transform from a laborintensive to a knowledge-intensive economy to overcome the middle-income trap. There is no one-size-fits-all model for transformation. Each country has its own transformation agenda and needs to identify the most appropriate strategies to achieve its goals.

\subsubsection{Virtuous Circle of Endowments, Transformation, and Quality Growth}

Transformation normally generates growth, as it did in East Asia, but growth is not always accompanied by transformation. Transformationled growth is distinct from, for example, commodity boom-led growth. Transformation-led growth could be high-quality growth and could generate further transformation. This implies that a virtuous circle of transformation and highquality growth could take place.

Generally speaking, given its attributes, quality growth enhances endowments, enabling further transformation. Inclusive growth, for example, could take the form of the participation of workers in the process of learning. Workers not only contribute to production but at the same time learn on the job, improving their learning capacity. Enterprises increase production, contribute to growth, and simultaneously achieve organizational learning and, often, innovation. Thus, if growth is genuinely inclusive and innovative, learning capacity should be strengthened through such growth. In this way, the quality of growth enhances the most important endowment, learning capacity, for further transformation and higher quality growth.

Furthermore, high growth is more likely to be sustained when it is inclusive because the strategy for such growth has wide social and political support. The report of the Growth Commission emphasizes this, arguing that "The Commission strongly believes that growth strategies cannot succeed without a commitment to equality of opportunity, giving everyone a fair chance to enjoy the fruits of growth" (Commission on Growth and Development 2008, 7). On the basis of an analysis of thirteen successful countries of long-term high growth (of which nine are East Asian economies), the report states that policy makers "must be trusted as stewards of the economy and their promise of future rewards must be believed. .... Their promise must also be inclusive. ... Governments forged an implicit or explicit social contract in support of growth, offering health, education, and sometimes redistribution. ...Absent this kind of political foundation, sustaining policies that promote growth is very difficult if not impossible" (26-27).

Similarly, sustainability - especially in terms of environment (another attribute of quality growth) - is indispensable (Hosono 2013a; b). Outcomes of high-quality growth, with all its attributes, could enhance essential endowments and enable further transformation and quality growth, generating a virtuous circle. Therefore, a growth strategy and industrial strategy with policies pertaining to endowments and transformation are vital for high-quality growth.

Andreoni, Chang, and Estevez's view on the relationship between quality of growth, transformation, and endowments is closely related to the virtuous circle among those elaborated above. The three authors "conceptualize quality of growth as a development process of production transformation led by the expansion of collective capabilities and resulting in the creation of good quality jobs and sustainable structural change" (Andreoni et al. 2019, 128).

A recent study on the estimation of wealth of nations by Lange et al. (2018) facilitates a better understanding of the relationship between endowments, transformation, and quality of growth from a scheme of capital assets accumulation similar to that proposed by Vinod et al. (2000) (see Further Discussion 2.2). 


\subsection{Strategies for Enhancement of Essential Endowments for Transformation and Quality Growth}

This section identifies three strategies to enhance each of the essential endowments.

\subsubsection{Strategy for the Enhancement of Learning Capacity}

Quality growth depends on learning capacity in several ways. Low learning capacity impedes the creation of new industries that take advantage of opportunities for transformation, even if other endowments, such as hard infrastructure, exist. If learning capacity is limited to a small part of the population of a country, inclusive growth is unlikely to be attained. More important, from a learning society perspective, inclusive growth has an intrinsic relationship with innovative growth. Growth can be really inclusive and, at the same time, innovative, when it takes full advantage of the talents of its entire population. Stiglitz and Greenwald (2014) point out that "our argument for why inclusive growth is so important goes beyond the standard one that it is a waste of a country's most valuable resource, human talent, to fail to ensure that everyone lives up to his or her abilities" (468).

Learning contributes to growth through increases in productivity as well as innovation. Learning enables the development of innovative, and specific, ways to make more efficient use of existing endowments. At the same time, learning enhances learning capacity - especially learning to learn as the most important endowment. This contributes to dynamic comparative advantage, thereby enabling industrial transformation and high-quality growth.

Learning and learning to learn are also essential for the green economy, which results in improved human well-being and social equity, while significantly reducing ecological risks and scarcity (Chap. 7). Widespread learning capacity facilitates sustainable growth because active participation is necessary for the success of many initiatives in areas such as preserving the environment and conservation of eco-diversity. Waste treatment, energy saving and efficient use of energy and resources, agroforestry, and management of water resources are also helped by inclusive learning. To enhance resilience to cope with disaster risks, innovative and inclusive approaches are indispensable. Disaster risk management is possible only with the participation of all residents and other stakeholders who, through mutual learning, have to find locally specific innovative solutions. Resilience is about learning to live with risks (Chap. 8).

To enhance capacity for learning, both quality education and learning by doing are key. As Stiglitz and Greenwald note, "One should see formal education and on-the-job training as complements, with the former designed to enhance the productivity of the latter" $(2014,57)$.

Ensuring complementarity between quality formal education (learning at school), on the one hand, and initiatives to strengthen learning by doing (learning at work), on the other, is one of the crucial challenges to create a learning society. From this point of view, one of the most effective approaches is enhancement of learning capacity to learn through formal education and through increasing opportunities of learning, especially learning to learn at the workplace. I elaborate on this by presenting the following case studies. I will discuss the intrinsic relationship between learning, transformation and quality growth further in Chap. 4.

\subsubsection{Case 2.1: Effective Approaches Toward Improvement of the Quality of Education in Science and Math Education}

In Central America, a regional program, "Me Gusta Matemática," and related programs have been implemented since 2006 based on the experiences of years of cooperation in Honduras and other countries. These programs have been 
built on three fundamental approaches. First, the student-centered teaching method was introduced to stimulate interest, curiosity and deepen the understanding of students by incorporating experiments, exercises, etc., instead of didactic teaching methods by teachers. Second, new ways of preparation of teaching plans and lesson materials were introduced. Third, efforts to improve teaching methods have been made with the participation of both the teaching staff of the school and members of the local community, adopting the method of "lesson study," widely practiced in Japan (Hosono et al. 2016, 41; Nishikata 2017).

With these approaches, new textbooks were prepared and the student-centered approach was introduced. For example, as the staff of the Honduras project members learned about Japanese textbook design, such as using figures and tables beside the main text, they started to recognize the importance of creating an easy-tounderstand textbook for children. After comprehensively reviewing any problems that they had experienced, they brainstormed a range of creative ideas: e.g., teaching young children how to use money and control spending is regarded as very important in Honduras. On the back of this, they suggested enriching the quality and quantity of practical calculation problems in first-grader's textbooks, and a more child-oriented textbook was created (JICA 2015, 9). Consequently, new textbooks, guidebooks for teachers and workbooks for students have been prepared for primary and lower secondary school students in Central American countries (Hosono et al. 2016).

The "Strengthening of Mathematics and Science Education" (SMASE) program that JICA has been promoting in Africa is based on two conceptual thrusts. The first is the idea that science and mathematics education in Africa must be upgraded by introducing a student-centered approach to lessons in classrooms. The second is the idea that in-service teacher training (INSET) can provide an effective opportunity to motivate teachers to brush up on their knowledge and skills. ${ }^{11}$
In science and mathematics classrooms in some African countries, teachers rarely undertake experiments or use teaching materials; instead, they write on blackboards and talk at their students, while the students simply listen and take notes. This way of conducting classes, often called "Chalk \& Talk," is rather common. Taught this way, students tend to develop a passive attitude in class without any willingness to engage with other students or think on their own. "Based on this observation, JICA has recognized the need to transform the teaching style of teachers in such a way that students are encouraged to participate in group activities, create hypotheses, do experiments, and to think on their own" (Shibuya 2013, 256). From the perspective of enhancement of learning capacity in formal education, the emphasis of SMASE on students' capacity to think on their own is particularly relevant.

SMASE-WECSA (SMASE Western, Eastern, Central and Southern Africa) network is a platform by which math and science educators across Africa can share and create practical wisdom through the exchange of each country's experiences and knowledge in math and science education. Approximately $60 \%$ of the 54 African countries have been involved in the network (Ishihara 2012, 84-85).

\subsubsection{Case 2.2: Effective Approaches to Strengthening Capacity to Learn to Learn by Learning by Doing}

Chapter 4 will review several capacity development (CD)-related programs implemented through international cooperation from the perspective of the enhancement of capacity for learning to learn. In all these programs, individuals and organizations learned to learn by learning by doing and by learning from others (i.e., mutual learning), and they co-created innovative solutions to the issues they needed to address.

The aim of the life improvement program is primarily to enable rural women to become 
aware of the numerous problems that exist in daily life and to address them as problems to be solved. As such, the objective of this program is learning to learn through learning by doing and making efforts to improve quality of life in its multiple dimensions. Rural women were encouraged to actively identify problems in their living conditions, set the issues, and formulate living improvement plans. As such, this initiative was not just about life improvement but also comprised a learning process that was particularly designed to enhance the capacity for learning to learn.

In the One Village One Product (OVOP) program, participants and their groups take part in multiple stages along a value chain, including production of raw materials, processing, marketing, and servicing. This provides a vehicle for maximizing learning opportunities. Such comprehensive knowledge, based on these experiences of learning by doing and mutual learning, has helped them to generate new ideas and create innovative products. By enhancing learning opportunities in their activities and sharing ideas among members of the OVOP group, they work constantly toward reaching a better marketing mix.

Through kaizen and related initiatives, ${ }^{12}$ quality control circles are an effective approach for frontline workers to contribute to and receive the benefit of mutual learning and to enhance capacity for learning to learn. Total quality management is also an effective approach for organizational learning. These approaches ensure that everyone lives up to her or his abilities and enables genuine inclusive and innovative growth (Chap. 4).

These programs have several common features: (1) easy entry points are available to initiate the learning process; (2) the costs and risks are low; (3) the focus is on learning by doing and mutual learning to cocreate innovative solutions; and (4) learning makes an intrinsic contribution to the particular objective being pursued - that is, life improvement, inclusive business, quality and productivity improvement, and incremental innovation, while at the same time enhancing the learning capacity to learn. I will elaborate more on these programs in Chap. 4.

\subsubsection{Strategy for Investing in Quality Infrastructure}

Regarding the relationship between infrastructure and growth, as Égert et al. (2009) emphasize, infrastructure investments can have a positive effect on growth that goes beyond the effect of the capital stock because of economies of scale, the existence of network externalities, and competition-enhancing effects. They argue that the evidence from cross-section regressions suggests that greater provision of infrastructure is associated with higher subsequent growth rates and that the link is nonlinear, with a potentially higher impact of additional infrastructure in countries with initially lower levels of provision. Infrastructure may not only have a positive impact on growth but also on some attributes of quality growth. Infrastructure such as transport and communication networks that encompass remote populations and provide a connection to world markets supports growth across sectors, geographic areas, and households, creating opportunities for quality growth. Seneviratne and Sun (2013) found that better infrastructure, both in quantity and quality, improves income distribution. This result, along with the proven role of infrastructure in enhancing productivity and growth, suggests that infrastructure development can double the effects on poverty reduction and inclusive growth. According to Seneviratne and Sun, for the five original member countries of the Association of Southeast Asian Nations (the ASEAN-5), removing infrastructure gaps not only raises potential growth but also spreads the benefits of growth more evenly.

Addison and Tarp (2016) focus on structural transformation and its interconnection with infrastructure and employment. They provide an overview of why infrastructure comprises an especially important dimension of transformation. Well-designed infrastructure encourages private investment, and infrastructure is intimately linked to job creation. Addison and Tarp state that "Aid in the livelihoods area is typically project-based, small-scale, and uncoordinated (UNU-WIDER 2014). It might create hundreds of jobs, but not the millions required to have 
impact at scale. In contrast, impact at scale is achieved by infrastructure of the right kind.... Infrastructure also creates jobs indirectly by stimulating economic activity, and trans-border transport infrastructure that reduces costs of exporting is a valuable job-creator.... Infrastructure is closely linked to industrial policy in building the capacities of countries to compete in the global economy for manufacturing and highvalue services, thereby creating good jobs (Page and Shimeles 2014). This is an area where Japanese aid has long-standing experience and has achieved considerable success in Asia (Shimomura 2016)" (Addison and Tarp 2016, 301).

Indeed, "Japan has been a consistent, and sometimes lonely, advocate of infrastructure development, even when other DAC donors and the World Bank reduced their resource allocation to this sector. From the Japanese perspective, it is encouraging that the international community is making a turnaround and starting to recognize the centrality of infrastructure, as seen, for example, in the recent debate on the post-2015 development framework" (Kato 2016, 9-10).

As such, from the quality growth perspective, quality infrastructure becomes one of the most featured aspects of the recent policy debate. First, Goal 9 of the SDGs aims to "Build resilient infrastructure, promote inclusive and sustainable industrialization and foster innovation" and Target 9.1 refers to "quality, reliable, sustainable and resilient infrastructure to support economic development and human well-being, with a focus on affordable and equitable access for all" (SDG9.1). In keeping with this goal, the declaration of APEC leaders meeting in Lima in 2016 under the theme of Quality of Growth and Human Development states that "We affirm our commitment to promote investment with a focus on infrastructure in terms of both quantity and quality. We reiterate the importance of quality infrastructure for sustainable economic growth. ...., [and] [we] are committed to translate this concept into actions including in ICT, energy and transport" (APEC 2016a, 8). ${ }^{13}$

In this regard, two APEC reports have identified the basic aspects of quality infrastructure
(APEC 2014b, 2016b) coinciding with the $G 7$ Ise-Shima Principles for Promoting Quality Infrastructure Investment. These G7 principles are closely related to attributes of quality growth - especially inclusiveness, sustainability, and resilience:

\begin{abstract}
Principle 1: Ensuring effective governance, reliable operations and economic efficiency in view of lifecycle cost as well as safety and resilience against natural disaster, terrorism and cyber-attack risks; Principle 2: Ensuring job creation, capacity building and transfer of expertise and know-how for local communities; Principle 3: Addressing social and environmental impacts; Principle 4: Ensuring alignment with economic and development strategies including aspects of climate change and environment at the national and regional levels; and Principle 5: Enhancing effective resource mobilization including through PPP (G7 Summit 2016, 1-2).
\end{abstract}

On the basis of these five principles, many effective approaches to constructing quality infrastructure can be envisaged. Michinoeki (Case 2.3) is one such approach. Many of the "corridors" programs discussed later (see Case 2.5) are examples of quality infrastructure as well. Numerous outstanding cases of quality infrastructure in diverse sectors, including railways, roads and bridges, airports and ports, energy, traffic systems, and disaster management, have been incorporated into the "Quality Infrastructure Investment Casebook” (MOFA 2015).

\subsubsection{Case 2.3: Effective Approaches to Constructing Quality Infrastructure: Michinoeki}

Michinoeki is a kind of public road infrastructure constructed in roadside areas. It is also a form of community infrastructure that promotes and contributes to the vitality of the region. Thus, Michinoeki should be planned and operated with the direct participation of local communities.

According to the "Study for Roadside Stations Master Plan" for Vietnam (JICA 2009), Michinoeki have the following five basic functions: road traffic management, local socio-economic development promotion, information provision, landmark, and rest and relaxation. ${ }^{14}$ Michinoeki 
are particularly related to secure growth and inclusive growth. The study states that Michinoeki may contribute to safety, comfortableness and convenience of road traffic thanks to the provision of resting spaces, as well as useful road traffic information. For inclusive economic development, Michinoeki may promote local employment, income generation, and economic development through sales of local products, job creation, and tourism promotion in surrounding areas. For social inclusion, Michinoeki may have positive impacts on local society through, for example, promotion of social participation by women, income generation of the poor or ethnic minorities, raising awareness of hygiene, improvement of information accessibility, and increasing training opportunities. They may also contribute to landscape improvement.

The Master Plan contemplated the targets for the distribution of Michinoeki (networks), accreditation, technical development for planning, construction and operation/management, development of database and information networks, establishment of Michinoeki development promotion organizations, budgetary planning, and provincial master plans.

The World Bank published guidelines for Michinoeki in 2006, drawing from experiences in Japan, Thailand, and pilot studies in Kenya and China. In the foreword and preface, it states:

This guideline brings together more than ten years of successful Japanese experience and practical work ....in East Asia and Africa. Today in Japan, there are more than 700 michi-no-eki road stations (michinoeki), and their positive impact on local economies, job creation, provision of public services for the local community (such as health care, education and training, and cultural activities) and regional integration is evident throughout the country... [Michinoeki] are different from other roadside services around the world for three reasons: (i) They are designed with the help of the communities and provide much stronger links between local communities and the users of the roads; (ii) they provide business opportunities for local residents; and (iii) they are possible venues for the provision of multiple public services such as, health care (including HIV/AIDS care), education and training activities, and cultural activities, as well as for the provision of the normal restaurant and commercial services. Given this unique structure, they have great potential as a tool for reducing poverty in many of the countries where the World Bank is working. All too often, inter-city roads effectively bypass the communities through which they pass without directly benefiting them (Yokota 2006, i, iii).

\subsubsection{Strategy for Strengthening Institutions}

Institutions are considered the basic determinants for long-term sustained economic growth (e.g., North 1990). From this perspective, Johnson et al. (2007) define good economic institutions as those that create effective property rights for most people, including protection against expropriation by the state (or powerful elites), and enforceable contracts between private parties. ${ }^{15}$ They also state that good economic institutions are essential in creating markets and sustaining efficient market transactions. This definition of institutions appears to be a narrow interpretation in terms of the quality of growth perspective. They recognize that "although this definition is far from requiring full equality of opportunity in society, it implies that societies where only a small fraction of the population have well-enforced property rights do not have good economic institutions" (2007, 7-8). de Soto $(1989,2000)$ asserts that a formal legal system is essential for poverty reduction to protect the property rights of the poor effectively and to enhance opportunities for them to engage in economic activities.

From a broader perspective, institutions matter for the most basic aspects of quality growth. Institutions to promote good governance, macroeconomic stability, the rules of law, and efficient administration are relevant since they promote growth opportunities that do not discriminate. For instance, progressive tax regimes as well as inclusive education and universal health-care institutions are foundations for 
inclusive growth. Acemoglu and Robinson (2012) made an important distinction between inclusive and extractive institutions. This distinction is useful for analyzing how types of institutions can determine the long-term prosperity of a locality, region, or nation. They claim that inclusive institutions can cause a virtuous circle of economic activities over a long period of time (Iizuka et al. 2016). In this virtuous circle, learning and innovation under inclusive institutions could be critical. Needless to say, institutions also matter for sustainability and resilience.

From an inclusive growth perspective, institutions related to small and medium enterprises are crucial. The Report of the High Level Panel of Eminent Persons on the Post-2015 Development Agenda (High Level Panel 2013) identifies priorities for the transformation of economies for jobs and inclusive growth. The report highlights the following first priority: "[to] create opportunities for good and decent jobs and secure livelihoods, so as to make growth inclusive and ensure that it reduces poverty and inequality" (8). The HLP report emphasizes the necessity of education, training and skills for people to respond to demands by businesses for more workers and to be successful in the job market (8-9).

Now in this "opportunities and capacities nexus," small and medium enterprises (SMEs) play a fundamental role. People, even if highly skilled, cannot take advantage of new opportunities alone. They need to start up enterprises to participate in opportunities or to be employed by large enterprises or SMEs to enjoy the benefits of such opportunities.

The opportunities/capacities nexus can be self-reliant when opportunities induce capacity development of enterprises and individuals. The increased capacity that results from this process, due to strengthened competitiveness, creates new opportunities and capacities - part of a 'virtuous circle' in which growth generates more growth. The second priority of the HLP report is to accelerate this autonomous process. The report states that "A second priority is to constantly strive to add value and raise productivity, so that growth begets more growth. Some fundamentals will accelerate growth everywhere-infrastructure and other investments, skills development, supportive policies towards micro-, small- and medium-sized enterprises, and the capacity to innovate and absorb new technologies, and produce higher quality and a greater range of products" (9).

Here, the report recognizes the necessity of supportive policies towards micro-enterprises and SMEs, together with infrastructure and other investments, skills development and so on. In other words, policies, especially towards SMEs, are considered needed to trigger and accelerate the process of growth generating more growth.

The Sustainable Development Goals (SDGs) emphasize the importance of SMEs in achieving the SDGs. One of the goals is to promote development-oriented policies and support productive activities, decent job creation, entrepreneurship, creativity and innovation, and encourage formalization and growth of micro-, small- and medium-sized enterprises (Target 8.3). Another goal is to increase access of smallscale industrial and other enterprises, in particular in developing countries, to financial services, including affordable credit, and their integration into value chains and markets (Target 9.3). ${ }^{16}$

JICA, based on years of cooperation in this area, ${ }^{17}$ published guidelines for SME promotion in 2013 (JICA 2013). This document suggests ways that institutions (as discussed above) could be established and strengthened in this particular area. It is a comprehensive and structured framework to achieve mid-term objectives and sub-targets with the following strategic goals: (1) Development of policies and institutions for SME promotion, including legal systems and institutional arrangements for policy implementation as well as the financial system; (2) Enhancement of competitiveness of businesses, including horizontal and vertical relationships among industries strengthening value chains, supporting businesses and human resources, technology and access to finance, and training of business and technical human resources. 


\subsubsection{Case 2.4: Effective Approaches to Strengthening Institutions that Facilitate \\ Participation of Small and Medium Enterprises in Industrial \\ Development}

From the perspective of 'institutions' for transformation and quality growth, the case of cooperation with Vietnam could provide a relevant example. In the early 1990s, as Vietnam took positive steps to rejoin the international community and rebuild a market-based economy, Japan provided substantial development assistance in such a way as to underpin and spur growing private investment in the country. Most of this development aid focused on infrastructure such as roads, railways, hydroelectric power generation and telecommunications. However, through technical assistance, Japan also offered valuable assistance toward economic policy formulation. Over a five-year period from 1995, a group of 20 academics led by Professor Shigeru Ishikawa worked closely with the Vietnamese government to design and develop proposals for a national economic policy. "The group's recommendations had an enormous impact on the Five Year Plan for Socio-Economic Development 2001-2005, which emphasized, among other things, the importance of domestic as well as foreign capital mobilization, rural and agricultural development alongside industrialization, and fostering the growth of SMEs as well as heavy industry" (JICA/JBIC 2008, 59). ${ }^{18}$ From the end of the 1990s, cooperation for SME promotion programs started focusing on implementation of the SME policy, SME promotion planning, and on strengthening of functions for supporting SMEs. Technical cooperation projects for education and training institutions were implemented in the 2000s and 2010s including programs for the Hanoi Industrial College, SME Technical Assistance Center, and Hanoi University of Industry. In the same period, technical cooperation projects (TCPs) for business personnel development, for local industry promotion for regional development, for industry statistics development, and for the creation of a legal system, were carried out (JICA 2013, 89).

\subsection{Strategies to Catalyze Transformation and Quality Growth}

Given the enhancement of essential endowments, and because of other factors, transformation takes place, but it does so along different paths. ${ }^{19}$ The strategies of transformation could be different depending on these paths. Among others, some of the main paths of transformation could be (1) catching-up transformation, (2) transformation through integration into regional or global value chains (GVCs), (3) transformation led by innovation, and (4) transformation with development of inclusive business. The following sections discuss one possible strategy for each of these types of transformation.

\subsubsection{Strategy for Catalyzing Sequential or Catching- Up Transformation}

In East Asia, a sequential or catching-up transformation well known in the region as the flyinggeese pattern (FGP) has taken place for decades. The process was enabled by dynamically changing endowments and comparative advantage. The three essential endowments for transformation for quality of growth played crucial roles.

Asia has grown faster than any other developing region, and a few of its economies have undergone a rapid and remarkable transformation. East Asian countries are most outstanding in this respect. "In the four decades from 1956 to 1996, East Asian living standards, as measured by real (inflation-adjusted) output per person, rose at a rate faster than has ever been sustained anywhere" (ADB 2008, 27). Of the ten economies around the world that recorded average increases of $4.5 \%$ a year or more during that period, eight were in East Asia ${ }^{20}$ (ADB 2008). This long-term high growth trend was not limited 
to East Asia, however. Other Asian economies rank in the upper tiers of world growth distribution: over those four decades, living standards in the sixteen "integrating Asian economies"21 analyzed in the ADB study (2008) grew at an average of $5 \%$ a year, whereas the world as a whole averaged only $1.9 \%$ Growth

The ADB study states that "East Asian economies specialized in simple, labor-intensive manufactures. As the more advanced among them graduated to more sophisticated products, less developed economies filled the gap that they left behind. The Japanese economist Akamatsu (1962) famously compared this pattern of development to flying geese" (ADB 2008, 26). The study elaborates on these aspects: "As Japan's exports shifted to more advanced products, East Asia's newly industrializing economies-Hong Kong, China; Republic of Korea; Singapore; and Taipei, China-filled the gap for labor-intensive products. In time, South East Asia and the People's Republic of China (hereafter, PRC) followed the similar trajectory" (ADB 2008, 29). These waves produced dramatic spurts of growth. Thus, "by the time the East Asian model had become widely celebrated (World Bank 1993, hereafter the East Asian Miracle study), it had been at work for four decades" (ADB 2008, 29).

In the same year that the ADB study was published, the Commission on Growth and Development published its report. It identified some of the distinctive characteristics of thirteen high-growth economies that have been able to grow at more than $7 \%$ for periods of more than twenty-five years since World War II. Of the thirteen economies, nine are East Asian economies (high performing Asian economies [HPAEs] and China). ${ }^{22}$ Referring to these economies of the "Growth Report," Lin argues that in East Asia there has been a sequential process of catchingup. He states that "the newly industrializing East Asian economies, for instance, exploited endowment structures similar to Japan's to follow that country's development in a flying-geese pattern" (Lin 2012b, 94). Aoki (2013, 2014) argues that the dynamics of the FGP are accompanied by a change of institutions. He proposes that the complex dynamics of demography, economy, and institutions - which are taking place in East Asia - could be conceptualized as FGP version 2.0, compared with FGP version 1.0 (based on Aoki's definition) originally proposed by Akamatsu (1962).

Although there has been an accumulation of literature on the $\mathrm{FGP}^{23}$ in Asia, the most remarkable fact is that FGP demonstrates the sequence of transformation among the economies of East Asia and is intrinsically related to the long-term high economic growth of these economies as a whole. In terms of public policy, this fact indicates the relevance of the strategy and policies of industrial transformation adopted by East Asian countries. After almost four decades of high rates of growth, and improvement of welfare with inclusive development (to be discussed later) in most of the East Asian economies, which account for more than $30 \%$ of the world's population, this growth was not just a coincidence. The East Asian Miracle study confirms this: "If growth were randomly distributed, there is roughly one chance in ten thousand that success would have been so regionally concentrated" (World Bank 1993, 2). ${ }^{24}$

Asian tigers started to pursue industrial development strategies as early as the 1960s, with other Asian countries following. As a Japan International Cooperation Agency/Japan Bank for International Cooperation (JICA/JBIC) study (2008) summarizes,

From the 1960 s through to the 80 s, the Asian
countries promoted industrialization in a strategic
manner by adopting import substitution policy
(ISP) and export oriented policy (EOP) ${ }^{25}$ for light
and heavy industry at different times and some-
times in a cyclical manner, thus fostering domestic
productive capacity while promoting export. Dur-
ing the second ISP period (for heavy and chemical
industry), many countries pursued EOP simulta-
neously. After this period, most Asian countries
shifted to EOP in the 1990 s. (JICA/JBIC 2008, 33)

In the mid-1980s, ASEAN countries were desperately attempting to transform their primary goods-based export structure to one oriented toward labor-intensive light manufacturing goods and further to technology-intensive manufacturing (Shimomura 2013). 
Since the 1980s, this FGP transformation has been reinforced by the development of electronics, automobiles, and other related industries, based on continuous innovation with consecutive expansion and deepening of regional and global value chains as well as supply chains. This process could be called "FGP + GVC-type transformation." I will elaborate later on this type of transformation.

The major driving force of East Asia's remarkable long-term growth has been industrial transformation from agriculture to labor-intensive light industries, and later, to knowledge-intensive industries led by FGP and the FGP + GVC process. This growth is affirmed by the fact that the reallocation of labor across sectors has been an important driver of productivity growth in several fast-growing East Asian economies. In China, it contributed $4.1 \%$ of $7.3 \%$ annual growth in aggregate labor productivity over the past decade (1999-2008); in Vietnam, it accounted for 2.6\% out of 4.2\% (World Bank 2012).

This sequential and catching-up transformation-led growth is closely related to the attributes of quality of growth in East Asia. Asian countries first promoted agricultural and rural development with the Green Revolution of the 1960s and 1970s and then started the intensive process of industrialization. From the end of the 1960s, in just a single decade, the introduction of high-yield rice and other primary crops, subsidies for fertilizers and other agricultural inputs, and the expansion of investment in irrigation improved agricultural productivity (JICA/JBIC 2008). From 1965 to 1988, growth in both agricultural output and agricultural productivity was higher in East Asia than in other regions. The East Asian Miracle study highlights the ways that East Asian governments have actively supported agricultural research and extension services to speed the diffusion of agricultural revolution technologies (World Bank 1993). This transformation has had substantial effects both on inclusive and pro-poor growth and on further transformation in these countries.
Increased agricultural output and productivity have direct effects on the welfare of rural populations. At the same time, increased production normally results in a fall in the real price of food, contributing to improvements for both urban and rural populations. Furthermore, higher agricultural productivity allows excess rural workers to migrate to urban areas, which enables the expansion of labor-intensive industries, generating further transformation.

The essence of the East Asian miracle was "rapid growth with equity" (World Bank 1993, 8) for at least the first three decades of sequential and catching-up transformation-led growth. ${ }^{26}$ Thus, we could say that "transformation with equity," considered the goal of development by UNECLAC (1990), was achieved in East Asia at least in the period between 1960 and 1990. The East Asian Miracle study emphasizes that "the HPAEs are unique in that they combine this rapid, sustained growth with highly equal income distributions" (World Bank 1993, 8).

The Growth Commission's 2008 report highlights the reasons why long-term high growth was achieved: the strategy for such growth was inclusive and was supported by a wide range of people in East Asia.

In spite of transformation-led long-term high growth, challenges remain in Asia. Regarding some of its attributes, such as inclusiveness and sustainability, certain setbacks can be observed in some economies of East Asia. This is why the quality of growth in Asia has been hotly debated, according to Haddad et al. (2015), who explain that this is understandable because Asia is a region that has achieved remarkable economic development. The "APEC Strategy for Strengthening Quality Growth," agreed on in 2015 by APEC leaders, in which most East Asian economies participate, articulates that, "while APEC as a region has made progress in achieving growth in all its attributes, much still remains to be done, particularly in making sure that the gains already achieved are further expanded and sustained" (APEC 2015, 1). 


\subsubsection{Case 2.5: Effective Approaches to Facilitate Regional Networks and Integration Through Development Corridors}

According to JICA, "Urban unipolar concentrations of economic activities and populations lead to an expansion of regional disparities and a reduction of national growth" (2016b, 1-2). The "corridors" approach considers a trunk corridor as the key development axis that will stimulate and increase economic activity in countries and regions. By combining the development potential of a region with corridor infrastructure improvement, a strategic regional development plan can enable the revitalization of an entire region and create a virtuous spiral of investment promotion and market expansion. Economic infrastructure such as roads and ports are of first importance to support the socio-economic activities in regional development. However, development of such infrastructure is not sufficient to reduce transportation costs due to imbalanced export-import demands. In addition, a region with a limited economic scale is unattractive as a market and not able to call for substantive investments. Therefore, it is important to push development forward by drawing an inclusive economic growth scenario, which realizes balanced national development and poverty reduction, by combining the development potentials of the region with corridor infrastructure improvement (JICA 2016b).

In Asia, the ADB launched the "Greater Mekong Sub-region (GMS) Development Program" in $1992 .{ }^{27} \mathrm{Six}$ countries in the Mekong region-Thailand, Vietnam, Laos, Cambodia, China, and Myanmar-participated. The ADB secretariat functioned as an intermediary between the member countries and donors, while also coordinating eleven programs, including economic development corridors in the region's North-South, East-West, and Southern areas. These programs covered nine priority areas: traffic and transportation, energy, communication, tourism, environment, human resource development, trade, investment, and agriculture. These development corridors promoted poverty reduction and economic growth by creating a belt that would link impoverished inland areas to port cities that had access to world markets. Moreover, electricity and communication infrastructure was developed in parallel with roads, bridges, and other transport infrastructure. Linkages to agriculture, mining resources, and tourism also were created based on this infrastructure. Free trade zones were established in the border areas and industrial parks were constructed. Because the success or the failure of the GMS corridor depended on collaboration between governments and the private sector, the GMS Forum took a number of steps to facilitate this collaboration. It sponsored workshops for the private sector, nurtured the development of regional resources and processing industries in all countries along the corridor, and proposed private investment to form industrial clusters at locations along the corridor.

JICA/JBIC (2008) emphasized that the GMS program was not originally launched by drafting and finalizing multilateral cooperative agreements, but rather it was based on a resultsoriented approach. It focused on the cooperation already established by bilateral agreements in areas where something could realistically be achieved. The agencies further stressed that, "as both parties benefited, the framework was gradually expanded to other countries and built upon the principle of comparative advantages. Such flexible pragmatism was a principle factor behind the comprehensive and synthetic GMS framework in the Mekong area development" (JICA/JBIC 2008, 55-56). Japan provided ASEAN countries "with support on the basis of the following pillars: (1) Strengthening connectivity (East-West and Southern economic corridors); (2) Promoting trade and investment (supporting energy supply, investment promotion and intellectual property rights enforcement); (3) Ensuring the sustainability of human security and the environment (disaster prevention, infectious disease control and so on)" (JICA 2016b, 4).

In Africa, in accordance with the framework of the Tokyo International Conference on African Development VI (2016-2018), as a part of the initiative "Quality Africa: Promoting 
Structural Economic Transformation through Economic Diversification and Industrialization," corridor developments are now being promoted. The three priority areas are the Northern Corridor of East Africa, the Nacala Corridor, and the West Africa Growth Ring. The initiative aims to accelerate trade expansion by promoting a corridor development approach to comprehensively integrate industrial development, social sector development, and economic infrastructure development, encouraging public-private partnerships from the master planning stage to the project implementation stage (JICA 2016b). ${ }^{28}$

\subsubsection{Strategy for Transformation Through Integration into Global Value Chains}

East Asian economies have been pioneers in transforming their industrial structure through participation in GVCs. East Asia was best able to take advantage of the expanding electronics industry. Although the share of electrical and electronic products in world trade of manufactured goods increased from 13.0 to $29.7 \%$ between 1970 and 2000, in East Asia, this share increased from 14.3 to $48.4 \%$ over the same period. In developing East Asia (i.e., East Asia except Japan), the share increased from 14.4 to $52.7 \%$ (to $55.7 \%$ in 2007) (Kumakura 2010). Later, the automobile industry significantly deepened GVCs.

This FGP + GVC-type transformation has been facilitated by intra-regional trade agreements in East Asia since the mid-1990s. Moreover, this type of transformation has been extended to other Asian countries. In "integrating Asian economies," 29 the share of parts and components trade in manufacturing trade increased from $24.3 \%$ in 1996 to $29.4 \%$ in 2006. The ADB (2008) study considers this a remarkable rise, because worldwide its share scarcely increased, edging up from 19.6 to $20.2 \%$ over the same period.

GVC trade grew rapidly from the 1990s and today its share of world trade increased to about $50 \%$. This growth is due to technological advances in transportation, information, and communications - as well as lower trade barriers -which together induced manufacturers to extend production processes beyond national borders. GVC growth was concentrated in machinery, electronics, and transportation, and the regions specializing in those sectors: East Asia, North America, and Western Europe (World Bank, 2019, 2).

Participation in GVCs creates opportunities for industrial transformation. Several features of GVC enable this. "In contrast to 'standard' trade carried out in anonymous markets, GVCs typically involve long-term firm-to-firm relationships. This relational nature of GVCs makes them a particularly powerful vehicle for technological transfer along the value chain. Firms have a shared interest in specializing in specific tasks, exchanging technology, and learning from each other" (World Bank 2019, 70). In short, through technological transfer and mutual learning, participating firms, including SMEs of developing countries, could improve the quality and productivity of their products. In the long run, trade through GVCs could facilitate industrial transformation. In this sense, GVCs with this feature can establish transformative (or transformational) relationships among participants, in contrast to the anonymous transactional relationship of most traditional trade. Furthermore, "through firm-to-firm relationships, GVC firms can also play an important role in on-the-job learning, and employer-sponsored training within GVCs can be an effective mechanism for skill development, economic growth, and wage increases... A case study of the impact of a Japanese multilateral company on skilled labor in Malaysia shows that the integration of the subsidiary's production network into its GVC spurred greater needs for skill development, particularly in management and engineering services" (World Bank 2019, 71). Case 2.6, presented below, on the Mexican car industry is closely related to these aspects of GVCs highlighted above.

The integration of small and medium enterprises (SMEs) into global and regional value chains is critical to making GVC-led transformation inclusive and innovative. A recent study 
by the Organization of Economic Co-operation and Development (OECD) and the World Bank (2015) focuses on inclusive GVCs, highlighting the policy options in trade and complementary areas for GVC integration by SMEs. As the report states, "Enhancing the integration into global markets of goods, services, investment, and knowledge of small and medium enterprises ... represents a challenge for growth and job creation in all countries, at all levels of economic development" (OECD and World Bank 2015, 14).

Regional aspects of inclusive value chains are emphasized in a study by UNECLAC (2014), which argues that the rise of value chains in the global economy has brought renewed attention to the centrality of the regional space. The main global production networks are structured around specific regions, largely because of the importance of geographic proximity when it comes to organizing production processes that are fragmented across a number of countries.

\subsubsection{Case 2.6: Effective Approaches for SME Participation in GVC Through Expansion of Supporting Industries}

The automobile industry provides a highly relevant case for exploring SME participation and regional aspects of GVCs. Opportunities will be increased by investments of automobile companies, which require high-quality and competitive automobile parts and services. Development of an automobile industry requires skilled labor and supporting industries to provide up to thirty thousand parts and components. Supporting industries and automobile assembly plants are closely related and provide mutual externality.

Development of supporting industries, composed mostly of SMEs, is essential for a competitive automobile industry. If the industry becomes more competitive, production and exports will increase, demanding more parts and services. This is a typical case of growth begetting more growth when it is accompanied by higher productivity or higher value-adding, which often is achieved through technology transfer and innovation. Supporting industries are structured with supply chains that normally incorporate three or more tiers of suppliers in the case of the automobile industry.

The ratio of exported cars to cars produced in Mexico was around $80 \%$ in 2014 . The increase of production and export of cars from Mexico has been remarkable: from less than 2.0 million cars in 2005 to over 3.4 million cars in 2014, of which 2.6 million cars were exported. This growth was enabled by years of efforts by the Mexican government and the private sector in such areas as human resource development, infrastructure development for highly efficient transport and logistics, automobile industry development policies, free trade agreements (North American Free Trade Agreement, European Union-Mexico Free Trade Agreement, and Japan-Mexico Economic Partnership Agreement), as well as institution-building of public and private entities related to the automobile industry. ${ }^{30}$

These factors have been extremely important for Mexico to receive foreign direct investment in support of its automobile industry and to enhance opportunities for SMEs to participate in the industry's development. SMEs had to improve their capacity to respond to opportunities for industries supporting car production so that they could develop and make the country's car industry competitive. To strengthen SMEs, laws on the development of competitiveness of micro, small, and medium enterprises were enacted in 2003.

Japan's role in automobile industry value chains has been growing. In the decade since the signing of the Japan-Mexico Economic Partnership Agreement (EPA), Japanese automakers have invested nearly US\$6 billion in Mexico. During the five-year period from 2012 to 2017, Mexico's car production increased from 3 to 4 million, while Japanese car manufacturers' participation expanded from 800 thousand to 1.33 million vehicles, an increase of $66 \%$. This increase in Mexico's car production has been accompanied by a rapid expansion of auto parts 
production in Mexico. The number of auto parts makers in the country increased from 956 to 2229 between the end of 2009 and the end of 2017. Behind this process of the growing participation of auto parts makers in automobile value chains, public and private cooperation programs between Mexico and Japan have played a key role in facilitating this process.

The main aspects of this process are elaborated by an Inter-American Development Bank study (IDB 2016, 27):

\begin{abstract}
In the case of Japanese auto firms in Mexico, public agencies on both sides have worked together on a variety of projects aimed at helping Mexican firms become suppliers for Japanese investors. These include efforts to overcome informational barriers - the Mexico office of the Japan External Trade Organization (JETRO) maintains an extensive database of local providers with the help of Mexico's trade promotion agency, ProMéxico - and providing direct capacity building for SMEs. In 2012, JICA initiated a program, with the help of Japanese firms, to increase the productivity of potential Mexican suppliers, through training in Japan's Kaizen management practices. In addition to these activities, the two governments established a "Committee on the Improvement of the Business Environment" in the context of the EPA, which meets regularly to discuss issues arising in the operations of Japanese firms in Mexico, from public security to support from local governments and tax issues. This committee has helped resolve issues and fostered a positive view of Mexico's business environment in Japan, encouraging Japanese SMEs to venture into the Mexican market.
\end{abstract}

In this context, several joint projects between Mexico and Japan for promoting industrial development, strengthening SMEs, and training workers have been implemented. This cooperation reflects the priorities of Mexico's industrial policy. ${ }^{31}$ Several cooperation projects have led to the realization of more structured and innovative cooperation to strengthen local supporting industries (i.e., SMEs) of the automobile industry, while adhering to the supply chain structure. The projects include "Support for Formation of Automobile Industry Cluster and Supply Chain," "Technical Support for Universities and Colleges of Engineering," "Automotive Supply Chain Development Project," and "Improvement of
Quality and Productivity of Small and Medium Supporting Industries for Automobile Production."

\subsubsection{Strategy for Innovation-Led Transformation}

Although these cases of transformation (sequential and catching-up transformation and participation in GVCs) are closely related to technological innovation in many ways, other cases of transformation have been led mainly by technological innovation. In these cases, technological innovation, along with other factors or endowments, was the key enabling factor of transformation. Although the former cases often are characterized by the adoption and adaptation of foreign technology, the latter cases often are characterized by breakthrough innovations or incremental innovations, which are normally not available elsewhere in the world at the time. An example of this is evident in the tropical agriculture and agroindustry, as well as agroforestry in tropical rainforests, for which industrial countries cannot provide technological innovation. Because the private sector cannot fully take the risk of investment in innovation, they underinvest in innovation activities, especially in developing countries (UN Industrial Development Organization [UNIDO] 2016, 151). To address this situation, governments need to lead or support investment in innovation. UNIDO (2016) lists the objectives, source, and agents of such support.

Hosono et al. (2016) have analyzed the case of Cerrado agriculture, in which technological innovation produced a profound transformation in the Central-West region of Brazil. In effect, agriculture, livestock, and agroindustry transformation in some Latin American countries has been outstanding. Brazil was a net importer of grain until the 1980s, when the country achieved a major breakthrough to become a net exporter of grain after converting its vast barren land into some of the most productive agricultural fields in the world. Further transformation was achieved 
by a deepening of the agroindustrial value chains, especially of meat and dairy products.

In the case of the Cerrado agriculture, from its inception through the early development phases, the public or semipublic sector took the initiative and made the necessary investments in research and development and in infrastructure. Later, public and private partnerships became essential for the formation of clusters and value chains as well as learning and innovation ecosystems around clusters. In the case of the Brazilian Cerrado, breakthrough innovations enabled the start-up of the Cerrado agriculture and continuous and incremental innovation followed, allowing agricultural production and agroindustry value chains to scale up (see Chap. 3).

Cases of agroforestry in Brazil, Panama, and Kenya illustrate the transformation enabled by farmers and their community with mainly incremental innovations for years of learning by doing in the tropical regions (see Chap. 7).

\subsubsection{Strategy for Inclusive Business- Led Transformation}

In addition to the strategies discussed thus far, people-centered transformation strategies deserve special attention. These strategies proactively support inclusive and sustainable activities in which the base of the pyramid (BOP) can participate. The use of inclusive business models, as proposed by the United Nations Development Program (UNDP/Growing Inclusive Markets 2008), could provide one such strategy. These models include the poor on the demand side as clients and customers (first category), and on the supply side as employees, producers, and business owners at various points in the value chains (second category) (emphasis added).

Inclusive business is an important pathway to realize industrial transformation and quality growth locally and also to focus on the BOP. For the first category of inclusive business, it is critical to produce goods at scale to make their price affordable for the poor and to expedite delivery. BOP businesses are different from a normal commercial business for a variety of reasons, including the limited purchasing power of low-income customers, the required innovative technology for consumption needs, the normally high levels of upfront investments, awareness and acceptance by users, and the difficulty of delivery (Kato and Hosono 2013). A comprehensive approach to addressing the constraints of inclusive businesses for the BOP is needed because (1) an affordable price is normally enabled by production at scale, which requires finance for scale; (2) delivery at scale is essential to make available new products for the BOP; and (3) partnership at scale with governments, NGOs, international organizations, and other stakeholders is needed as well.

For the second category of inclusive business, it is essential to create and commercialize competitive products and services based on local resources, to support self-reliance and creativity, and to develop human resources. By learning about improvements to their livelihood, communities and their members will become more conscious of their needs (and challenges) and of BOP products to satisfy them. This approach enables communities to become involved in "participatory platforms for inclusive products and service design" (Caneque and Hart 2015, 8) on the demand side of inclusive business. At the same time, it enables and strengthens their capacity on the supply side to become employees, producers, and business owners at various points in the value chains by participating in inclusive business. OVOP programs have resulted in a promising model of inclusive business from the supply side (i.e., the second category) (Chap. 4).

\subsubsection{Case 2.7: Effective Approaches to Catalyzing Local Transformation Through Inclusive Business}

As regards inclusive business for the demand side of the BOP (first category), the case of longlasting insecticide-treated mosquito nets (LLINs) appears to be highly relevant. Looking at the history of the mainstreaming of LLINs, we can extract several dominant factors that enabled successful scale-up. First, the invention of the 
Olyset net by Sumitomo Chemical was an indispensable technological breakthrough at the core of the scaling-up process. It was a major technical innovation that resolved the problems that traditional insecticide-treated nets (ITNs) could not overcome. This technology was transferred royalty-free to a local company in Tanzania. A second enabling factor was the WHO's decision to mainstream LLINs as a means of fighting malaria. A third factor was the partnership of a wide range of actors as represented by the Olyset Consortium, without which the technological innovation would not have become commercially viable in developing countries (Kato and Hosono 2013).

The partnership provided an important contribution to making this technological innovation marketable. It enabled local production in Africa, leading to cost reductions and increased affordability for local residents, as well as systems to be developed for distribution and follow-up. Meanwhile, partly due to global initiatives to achieve universal coverage, the market for LLINs has expanded considerably. The number of suppliers with the recommendation of the WHO Pesticide Evaluation Scheme (WHOPES) has increased from three in 2007 to ten in 2011. The total number of ITNs supplied annually (mostly LLINs) increased from 5.6 million in 2004 to 145 million in 2010 (Kato and Hosono 2013, 227).

Another example of an inclusive business on the demand-side can be seen in the performance of the Yakult system. ${ }^{32}$ This model was introduced to Grameen Danone in Bangladesh, a joint venture of Microfinance Institution Grameen and the French Dairy Company, Groupe Danone. ${ }^{33}$ Grameen Ladies deliver a yogurt fortified with micro-nutrients to decrease malnutrition for the children of Bangladesh. The first plant started production in 2006 (UNDP 2010, 39).

Several points can be considered as factors that have enabled the success of this model on the demand side (first category). First, at the base of the company's success was its unique business model, which was able to tap into people's latent demands for beverages with health benefits at affordable prices. This business model comprised, most notably, an attractive product (quality and price) and the company's unique home delivery system using the Yakult Ladies. This home delivery system enabled customers to purchase the product without needing to make trips to the supermarket or other shops, in small quantities, from people with whom they were acquainted and on whom they could rely, while at the same time receiving information on the possible benefits of the product. Communication with customers was greatly facilitated by the Yakult Lady system. The system also provided new job opportunities, particularly to women (many of them single mothers), making them more self-reliant in economic terms. The company's success in developing countries shows that the product has succeeded in tapping into the latent demands of people, especially the poor.

The rapidly growing sesame value chain in Paraguay can be considered as an example of inclusive business for the supply side of the BOP (second category). Indeed, it is a case of inclusive business-led transformation with strong effects on social inclusion. The pioneering company was Shirosawa Co., which started the experimental production of sesame in 1989. The company decided to work with small farmers in 1993. It took four years to develop a high-quality variety, Escoba. This technological innovation achieved a breakthrough in creating a new and competitive food value chain in Paraguay. Between 1995 and 1996, this variety was rapidly disseminated and production of sesame increased from $120 \mathrm{t}$ in 1994 to $1200 \mathrm{t}$ in 1996 , and to $8343 \mathrm{t}$ in 1999/2000 (UNDP 2008, 54). Other companies participated in sesame production, following the inclusive business model of Shirosawa Co., and the amount of production in Paraguay increased steadily to 51,219 t. in 2008/2009 (USAID 2009, 25).

The number of small farms producing sesame increased from 5000 in 1999 to 35,000 in 2005 and to around 50,000 in 2015. Each farm cultivates sesame over 1-2 h. Sesame is today one of the most important export products of Paraguay. Shirosawa and seven other sesame companies provide technical assistance to farmers through their extension experts, provide finance to 
farmers, and buy sesame from them. USAID (2009) highlights the importance of the contribution of Shirosawa Co.: "It demonstrated that sesame production is adequate for small farmers; it diffused the "culture of quality" among farmers; and it introduced a system of traceability involving farmers." Today around $70 \%$ of white sesame imported to Japan is from Paraguay.

\subsection{Conclusion}

The strategies and case studies discussed in this chapter show that quality growth needs to be discussed in the context of transformation, which is the key driver of growth and a determinant of the various attributes of growth. As transformation is closely related to changing endowments and dynamic comparative advantage, the central theme has to be the relationships among these endowments, transformation paths, and attributes of quality growth.

It is clear that the enhancement of endowments and the transformation do not take place automatically. These processes are normally endogenous, but they need to be catalyzed or facilitated by industrial strategies and policies. As a corollary, it might be realistic to design policies and measures to attain the desired attributes of quality growth alongside the development of specific industries and their value chains, as transformation is taking place, while remembering specific transformation paths and quality growth agendas.

Transformation and quality growth need to be considered in a holistic manner, as a comprehensive target to be achieved. The APEC Growth Strategy could be regarded as a pioneering initiative with a holistic framework for attaining such a target. In developing a distinct transformation agenda for each country, the nature of quality growth should be fully taken into account, bearing in mind the interrelationships, synergy, sequences, and trade-offs among them.

As the transformation agenda differs between countries with distinctive characteristics, policies and measures to transform these different economies and attain the desired attributes of quality growth also would be different. No standard model addresses the challenges of transformation and quality growth. Each country requires a distinct combination of strategies as well as effective approaches toward realizing such strategies. The approaches discussed in this chapter may provide some means of envisioning alternative strategies.

The interrelationships among endowments, transformation, and quality growth are highly complex, and this chapter has covered these aspects only in part. Therefore, they deserve further in-depth analysis.

\subsection{Further Discussion 2.1: Overview of Recent Trend of a Consensus on the Importance of Transformation and Quality of Growth in East Asia, Latin America, and Africa}

In recent policy debates on growth and development, economic transformation has featured, together with quality of growth. The Report of the High-Level Panel of Eminent Persons on the post-2015 Development Agenda is titled "A Global Partnership: Eradicate Poverty and Transform Economies through Sustainable Development" (hereafter referred to as "The Report of HLP"). The panel concluded that the post-2015 agenda needs to be driven by five big transformational shifts, including a call for the transformation of economies for jobs and inclusive growth. The above-cited United Nations 2030 Agenda declares that "We are determined to take the bold and transformative steps which are urgently needed to shift the world on to a sustainable and resilient path"(United Nations 2015, 2).

Thus, there now seems to be more of a consensus on the importance of quality of growth, on the one hand, and transformation on the other. We can also confirm this trend in some of the main developing regions of the world, including East Asia, Latin America, and Africa. 
Some East Asian countries have been pioneers of industrial transformation. Over the last four decades, Asia has grown faster than any other developing region, and a few of its economies have undergone a rapid and remarkable transformation (ADB 2013, iii). In East Asia, as early as the 1960 s, countries started to implement policies to transform themselves from agriculture-based to industry-based economies, and then from labor-intensive industries to knowledge-intensive ones. The first movers were Asian tigers such as Korea, Chinese Taipei (Taiwan), and Singapore. Other East Asian countries followed. However, in spite of this remarkable trajectory, concerns over economic transformation have now been renewed in Asia. The Asian Development Bank Annual Report 2013 feature was “Asia's Economic Transformation: Where to, How, and How Fast?" The report states: "Developing Asia needs to make a significant and qualitative leap in structural transformation" (xxix). Almost simultaneously the United Nations ESCAP published a report titled "Shifting from Quantity to Quality: Growth with Equality, Efficiency, Sustainability and Dynamism." It presented a holistic framework that distinguished between three dimensions of quality of growth: environmental, social, and economic (UNESCAP 2013, 7).

In Latin America, the United Nations ECLAC's flagship report 2012, titled "Structural Change for Equality: An Integrated Approach to Development," featured the theme of transformation with equality. This drew on ECLAC's seminal proposal titled "Transformación Productiva con Equidad," published in $1990 .{ }^{34}$ The 2012 report states that "social equality and economic growth that transforms the production structure are not incompatible, and that the challenge lies in finding the synergies between them" (UNECLAC 2012, 14). Here, the relationship between transformation and growth with equality is the central theme. In 2014, the InterAmerican Development Bank (IDB) published its flagship report, "Rethinking Productive Development: Sound Policies and Institutions for Economic Transformation." This report states that in Latin America, "while the accumulation of factors of production, both physical and human capital, has helped to narrow the gap with the United States, productivity is low and its poor performance continues to be a drag to income convergence," and that "in contrast, other successful developing regions such as the East Asian tigers have been able to sharply close their productivity gap." The report focuses on the "important role of active policies for advancing economic transformation and sustained growth" in Latin America (IDB 2014, 3).

I elaborated on the recent trend of stronger consensus on the importance of transformation and quality of growth in Africa at the beginning of this chapter, referring to documents of $\mathrm{AU}$, UNECA, and ACET.

\subsection{Further Discussion 2.2: Transformation and Quality of Growth from Capital Assets Accumulation Perspective}

The relationship between endowments, transformation, and quality of growth could be discussed from a "capital assets accumulation" perspective. Vinod et al. (2000) proposed a simple scheme of how human capital, natural capital, and physical capital contribute to economic growth and welfare: "Physical capital contributes to welfare through economic growth." "Human (and social) capital and natural capital (and environmental) capital also do that; they are also direct components of welfare." The three capitals have mutual externalities: "Human, and natural capital also contribute to the accumulation of physical capital by increasing its returns. Physical capital increases returns to human capital and natural capital and, if markets reflect this, their accumulation." Furthermore, the three capitals could contribute to technological progress and total factor productivity growth: "Investments in physical, human, and natural capital, together with many policy reforms, contribute to technological progress and the growth to total factor productivity, thereby boosting growth" (xxxvi). 
Related to this scheme is "wealth account" based on measurement of capital assets accumulation, in which the amount of the three types of capital, natural capital (R), intangible capital $(\mathrm{H})$, and produced capital $(\mathrm{P})$, is estimated (World Bank 2011; Lange et al. 2018). ${ }^{35}$ In this estimation, natural capital comprises agricultural land, protected areas, forests, minerals, and energy; produced capital comprises machinery, structures, and equipment; intangible capital includes measures of human, social, and institutional capital (World Bank 2011, 4). Although intangible capital is measured as a residual, and agricultural land is not included in the estimation of natural capital, this wealth account facilitates the understanding of changing endowments and quality of growth.

Investment in $(\mathrm{H}),(\mathrm{R})$, and $(\mathrm{P})$, and their mutual externalities change part of endowments. The above "growth accounting" type framework illustrates how $(\mathrm{H}),(\mathrm{R})$, and $(\mathrm{P})$ interact, and how a part of the process of "changing endowments/transformation/quality growth (CTG)" takes place. In this process, changing endowments through investments in $(\mathrm{H})$ and $(\mathrm{P})$, together with externalities and technological progress, produce industrial structure transformation with a reallocation of labor across sectors and subsequent increase of total factor productivity (TFP) growth (productivity-enhancing structural change). It has been one of the most commonly observed processes as an important driver of productivity growth (and consequently sustained growth) in several East Asian countries. "In China, it contributed 4.1 percentage points of the $7.3 \%$ annual growth in aggregate labor productivity over the past decade; in Vietnam, it accounted for $2.6 \%$ out of 4.2." (World Bank 2012, 100).

On the other hand, according to the estimation of the wealth of nations, intangible wealth is the largest single component of wealth in all income groups of countries, and the fastest growing one as well (World Bank 2011, 4, 6). On the other hand, the impact of overexploitation of natural capital has been sizable in some countries. In 1997 , gross domestic savings were about $25 \%$ of gross domestic product (GDP) in the developing world. Corrected for the depletion of environment capital, however, genuine domestic savings were only an estimated 14\% of GDP (Vinod et al. 2000: xxvii).

Summing up, estimation of the wealth of nations by Lange et al. (2018) is related to the scheme of Vinod et al. (2000) and facilitates understanding of changing endowments and quality of growth as well as transformation.

\section{Notes}

1. This UN plan of action on Sustainable Development Goals (SDGs) was adopted by the UN General Assembly in 2015; see United Nations (2015), “Transforming Our World: The 2030 Agenda for Sustainable Development," https://sustainabledevelopment.un.org/ content/documents/21252030\%20Agenda $\% 20$ for\%20Sustainable\%20Development \%20web.pd.

2. The APEC Growth Strategy's definition of quality of growth, which focused on five desired attributes, appears to be one of the most widely agreed-on and most comprehensive definitions. It draws on the outcome of discussions on these attributes over a decade, and is reviewed in the following sections.

3. See, for example, Asian Development Bank, Key Indicators for Asia and the Pacific 2013: Asia's Economic Transformation: Where to, How, and How Fast? (ADB 2013); UN Economic and Social Commission for Asia and Pacific, Shifting from Quantity to Quality: Growth with Equality, Efficiency, Sustainability and Dynamism (UNESCAP 2013); UN Economic Commission for Latin America and the Caribbean, Structural Change for Equality: An Integrated Approach to Development (UNECLAC 2012); InterAmerican Development Bank, Rethinking Productive Development: Sound Policies and Institutions for Economic Transformation (IDB 2014); UN Economic Commission for Africa, Making the Most of Africa's 
Commodities: Industrializing for Growth, Jobs and Economic Transformation (UNECA 2013); African Center for Economic Transformation, "2014 African Transformation Report: Growth with Depth" (ACET 2014).

4. The report emphasizes that what African countries need is growth with depth: "More Diversification, more Export competitiveness, more Productivity increase, more Technological upgrading, and more improvements in Human well-being" (the title of the ACET report, "Growth with Depth" is itself an acronym drawn from the names of the five elements). It states: "Only by doing so can they ensure that growth improves human well-being by providing more productive jobs and higher incomes and thus has everyone share in the new prosperity" (ACET 2014, 1).

5. Aggregate productivity increases when the most productive sectors expand. This effect, referred to as productivity-enhancing structural change, is well documented in the case of labor shifts from agriculture to industry and services. Reallocation of labor across sectors has been an important driver of productivity growth in several fast-growing East Asian countries; see World Development Report 2013: Jobs (World Bank 2012, 100).

6. Regarding factor endowments, it is essential to take into account mobility of capital and highly skilled labor, rapid technological change, and evolving global value chains. For a discussion of this aspect, see Noman and Stiglitz (2017 12-13). Demographic transition also matters for long-term comparative advantage.

7. This is based on Japan's view of economic development and its experiences (see Hosono 2016, 173). In a similar manner, JICA/JBIC $(2008,17)$ considers infrastructure, human resources, and credit markets as fundamental growth-driving functions. See Hosono (2016) and JICA/JBIC (2008).

8. Japan's Official Development Assistance white paper states that achieving economic growth requires improving the investment environment, which involves policy and institution building, human resources development, strengthening basic infrastructure, attracting foreign direct investment, and expanding trade. Japan has long insisted that economic growth through infrastructure development, etc., is crucial to poverty reduction, and has incorporated this viewpoint in its ODA policies. See Japan's Official Development Assistance 2005 (MOFA 2005, Part I, Sect. 2).

9. This means "I like mathematics" in English.

10. "Lesson study" is a method in which teachers observe classes with related persons inside and outside of school and consider approaches to improve classes and their own teaching skills. In Japan, it has spread gradually since the Meiji Era, and is now commonly practiced at schools. Japan's experience is being used in faraway countries, including African countries, in order to provide children with a better education (JICA 2015, 5; Isoda et al. 2007).

11. This and the next paragraphs draw heavily from Shibuya (2013).

12. Kaizen is a management philosophy and know-how system that brings about continuous improvement of productivity and quality. It is a philosophy that has contributed to the development of Japan, especially in manufacturing industries. More recently, it has proved to be valid for use in other countries, cultures, and sectors. Kaizen is a human-centered approach that fosters teamwork, self-reliance, creativity, and ingenuity; see JICA (2016a).

13. The concept of "quality infrastructure" was first used in the APEC Leaders Declaration in 2013. The APEC Connectivity Blueprint was adopted the following year; see APEC (2014a).

14. Service areas on expressways are not exactly the same as Michinoeki, but similar in the way that they are installed for traffic safety and comfort of drivers and passengers. 
15. They compared Africa today with countries that were similarly weak in the past in terms of their institutional development and yet managed to escape from poverty. Inherited institutional weaknesses persist in Africa, and internal conflict and societal fractionalization remain concerns. However, the East Asian experience demonstrates that some institutional weaknesses can be escaped; see Johnson et al. (2007, 36-37).

16. From this perspective, East Asian experiences seem highly relevant because financial institutions played an important role in industrialization and inclusive growth in the region. The East Asian governments created financial institutions to provide long-term loans at low interest rates, helping their countries to promote economic development through industrialization and infrastructure building. At the same time, they encouraged inclusive development by providing credit to agriculture and small and medium firms. The World Bank (1993) highlighted the following three aspects: East Asian governments created a wide range of financial institutions to fill perceived gaps in the types of credit provided by private entities. They addressed the need for long-term credit for industry by creating development banks. Most have also created specialized institutions that provide credit to agriculture and small firms.

17. JICA (2013, 86-223) summarizes all cooperation programs for SME promotion carried out by JICA since the 1970s and presents lessons learned from several such programs.

18. In this context, cooperation programs related to industrial development including SME promotion in Vietnam implemented by JICA were "Technical Cooperation for Development Planning and Research (DS) for Development of Industries in the Hanoi Region" and later "DS for the Hoa Lac and Song May Regions" (1990s); "DS for Steel Industry Promotion" (1990s). In the 2000s and 2010s, cooperation programs for the "Food Industries Research Institute" for the "Master Plan Formulation for the Electronics Industry," and for "Establishment of a Skill Testing System" were implemented.

19. The ADB report on transformation explains: (1) countries' structural transformation (ST) is driven by demand and supply factors; (2) demographic and geographic variables and country size shape the pattern of ST; (3) good organizational capabilities that encompass all of the tacit knowledge necessary to produce a good or deliver a service allow faster ST; and (4) specific policies and actions, institutions, and politics often work jointly to determine the direction and pace of ST (ADB 2013, 5).

20. The eight economies are the People's Republic of China, Japan, Malaysia, Thailand, and so-called Asian tigers (Hong Kong, Republic of Korea, Singapore, and Chinese Taipei). The eight high-performing Asian economies (HPAEs) of the World Bank's study on the East Asian Miracle (cited later) are the Asian tigers, and Indonesia, Japan, Malaysia, and Thailand.

21. The sixteen "integrating Asian economies" are, in addition to the eight economies, the other ASEAN countries (Brunei Darussalam, Cambodia, Indonesia, Lao People's Democratic Republic, Myanmar, Philippines, and Vietnam) and India.

22. Regarding HPAEs, see footnote 20.

23. FGP is also referred to as flying wild geese (FWG); see Ippei Yamazawa, "Flying Wild Geese Pattern in Pacific: Pattern of Industrial Development among Asian Countries" (Yamazawa 1990). For literature on FGP, see Hosono (2017), Asia Pacific and Latin America: Dynamics of Regional Integration and International Cooperation.

24. In addition, The East Asian Miracle study states that, since 1960, the HPAEs have grown more than twice as fast as the rest of East Asia, roughly three times as fast as Latin America and South Asia, and five 
times faster than sub-Saharan Africa. They also significantly outperformed the industrial economies and the oil-rich Middle East -North Africa region. Between 1960 and 1980, real income per capita increased more than four times in Japan and the Four Tigers and more than doubled in the Southeast Asian NIEs (World Bank 1993, 2).

25. IS and EO were used instead of ISP and EOP in the cited document.

26. The East Asian Miracle study classified countries of the world by a combination of the levels of GDP growth rate per capita and income inequality between 1965 and 1989: "There are 7 high growth, low-inequality economies. All of them are in East Asia," namely HPAEs except Malaysia (World Bank 1993, 30). The HPAEs have also achieved 'unusually low and declining levels of inequality, contrary to historical experience and contemporary evidence in other regions' (Kuznets 1955)" (World Bank 1993, 29-30; Kuznets 1955, 1-28).

27. This paragraph draws heavily from JICA/JBIC, Report of the Stocktaking Work on the Economic Development in Africa and the Asian Growth Experience (JICA 2008).

28. In compliance with the commitment made at TICAD V, Japan cooperated in formulating ten strategic master plans for comprehensive corridor development in Africa. "The comprehensive corridor development master plan elaborates a relatively longterm (20 to 30 years) policy, as well as identifies short-term priority projects, considering rapid population growth and urbanization trend. It enhances the feasibility and effectiveness of corridor development by strategically connecting natural and human resources with industries and infrastructure along corridor(s) in regionwide crossing borders. It also strategically aims at improving the investment attractiveness of the region, and strengthening regional connectivity and integrity" (JICA 2016b, 3; JICA 2019, 4).

29. See footnote 21 in regard to integrating Asian economies.
30. For further information on Japanese investments and cooperation with the Mexican car industry, see Japan and Latin America and the Caribbean: Building a Sustainable Trans-Pacific Relationship (IDB 2013, 33-35); and A Virtuous Cycle of Integration: The Past, Present, and Future of Japan-Latin America and the Caribbean Relations (IDB 2016, 25-27).

31. These projects of cooperation are "Study on Promotion and Development Plan of Supporting Industries" in 1996-1997, "Study on Technology Transfer" in 1997-1999, "Press Process Technology Improvement Project" in 2006-2009, "Study on SMEs' Human Resources Development" in 20082009, and "Plastic Molding Technology Human Resources Development Project" in 2010-2014.

32. Yakult Honsha, Co., Ltd. is a Japanese fermented-milk drink manufacturer founded in 1935. Its main product is a probiotic drink (live microorganisms that provide health benefits by improving the balance of intestinal flora), sold under the brand name of Yakult, which contains a fortified lactic acid bacterium with benefits for human health. It is considered an effective drink for preventive health care, especially for children, to address infectious disease and malnutrition. Though a mid-sized company by Japan's standards, the company is quite well known for its unique business model, both in Japan and abroad. Currently, the company's overseas operations cover 32 countries, and the number of overseas Yakult Ladies amounts roughly to 42,300 , many of whom are in developing countries.

33. For this initiative, Katsuhiro Hirano, Executive Director of Yakult, was invited to be a visiting director of Danone from 2004 to 07. In India, Yakult Danone India, a joint venture, was formed in 2005.

34. The English version of this publication is titled "Changing Production Patterns with Social Equity" (UNECLAC 1990).

35. New estimation of 'Wealth of Nations'. 


\section{References}

Acemoglu D, Robinson J (2012) Why nations fail: the origins of power, prosperity and poverty. Crown Business, New York

ACET (African Centre for Economic Transformation) (2014) 2014 African transformation report: growth with depth. ACET, Accra, Ghana

ADB (Asian Development Bank) (2008) Emerging Asian regionalism: a partnership for shared prosperity. ADB, Manila

ADB (2013) Key indicators for Asia and the Pacific 2013: Asia's economic transformation: where to, how, and how fast? ADB, Manila

Addison T, Tarp F (2016) Lessons for Japanese foreign aid from research on aid's impact. In: Kato H, Page J, Shimomura Y (eds) Japan's development assistance: foreign aid and the post 2015 agenda. Palgrave Macmillan, New York, pp 295-309

Akamatsu K (1962) A historical pattern of economic growth in developing countries. Dev Econ 1(1):3-25

Andreoni A, Chang H-J, Estevez I (2019) New global rules, policy space, and quality of growth in Africa. In: Kanbur R, Norman A, Stiglitz J (eds) The quality of growth in Africa. Columbia University Press, New York, pp 112-145

Aoki M (2013) Comparative institutional analysis: theory, corporations and East Asia. Selected Papers of Masahiko Aoki. Edward Edgar, Cheltenham

Aoki M (2014) Keizaigaku Nyumon [Introduction to economics]. Chikuma Shobo, Tokyo

APEC (Asia Pacific Economic Cooperation) (2010) The APEC leaders growth strategy. APEC, Yokohama, Japan

APEC (Asia Pacific Economic Cooperation) (2014a) APEC connectivity blueprint for 2015-2025. APEC, Beijing

APEC (Asia Pacific Economic Cooperation) (2014b) APEC guidebook on quality of infrastructure development and investment. APEC, Beijing

APEC (Asia Pacific Economic Cooperation) (2015) APEC strategy for strengthening quality growth. APEC, Manila

APEC (Asia Pacific Economic Cooperation) (2016a) 2016 leaders' declaration. APEC, Lima, Peru

APEC (Asia Pacific Economic Cooperation) (2016b) Study on infrastructure investment in the APEC region. APEC, Lima, Peru

Cabinet Office (Japan) (2015) Development cooperation charter. Cabinet Office, Tokyo

Casado Caneque F, Hart SL (2015) Base of the Pyramid 3.0: sustainable development through innovation and entrepreneurship. Greenleaf Publishing, Sheffield, UK

Commission on Growth and Development (2008) The growth report: strategies for sustained growth and inclusive development. World Bank, Washington DC de Soto H (1989) The other path: the invisible revolution in the third world. Harper Collins, New York de Soto H (2000) Mystery of capital: why capitalism triumphs in the west and fails everywhere else. Basic Books, New York

Égert B, Koźluk T, Sutherland D (2009) Infrastructure and growth: empirical evidence. OECD Economics Department Working Paper No. 685. OECD, Paris

G7 Summit (Group of Seven) (2016) G7 Ise-Shima principles for promoting quality infrastructure investment. G7, Ise-Shima, Japan

High-Level Panel of Eminent Persons on the Post-2015 Development Agenda (2013) A new global partnership: eradicate poverty and transform economies through sustainable development. United Nations, New York

Haddad L, Kato H, Meisel N (2015) Introduction. In: Haddad L, Kato H, Meisel N (eds) Growth is dead, long live growth: the quality of economic growth and why it matters, pp 1-16. JICA, Tokyo

Hosono A (2013a) Industrial transformation and quality of growth. In: Haddad L, Kato $\mathrm{H}$, Meisel $\mathrm{N}$ (eds) Growth is dead, long live growth: the quality of economic growth and why it matters, pp 267-300. JICA, Tokyo

Hosono A (2013b) Catalyzing an inclusive green economy through South-South and triangular cooperation: lessons learned from three relevant cases. In: Kato H, Honda S (eds) Tackling global challenges through triangular cooperation, pp 53-80. JICA, Tokyo

Hosono A (2016) Catalyzing transformation for inclusive growth. In: Kato $\mathrm{H}$, Page J, Shimomura Y (eds) Japan's development assistance: foreign aid and the post-2015 agenda. Palgrave McMillan, New York, pp 169-187

Hosono A (2017) Asia Pacific and Latin America: dynamics of regional integration and international cooperation. International Trade Series 132. UNECLAC, Santiago, Chile

Hosono A, Kozaki T, Fujishiro K, Kishiwada H (2016) Desarrollo Inclusivo en América Central y la República Dominicana. SICA (Sistema de Integración Centroamericana) and JICA, San Salvador and Tokyo

Hosono A, Magno C, Hongo Y (eds) (2016) Development for sustainable agriculture: The Brazilian Cerrado. Palgrave McMillan, New York

IDB (Inter-American Development Bank) (2013) Japan and Latin America and the Caribbean: building a sustainable trans-pacific relationship. IDB, Washington, DC

IDB (Inter-American Development Bank) (2014) Rethinking productive development: sound policies and institutions for economic transformation. IDB, Washington, DC

IDB (Inter-American Development Bank) (2016) A virtuous cycle of integration: the past, present, and future of Japan-Latin America and the Caribbean Relations. IDB, Washington, DC

Iizuka M, Hosono A, Katz J (2016) Conclusions and policy implications. In: Hosono A, Iizuka M, Katz J (eds) Chile's Salmon Industry: policy challenges in managing public goods. Springer, Tokyo, pp 195-205 
Ishihara S (2012) Network-type cooperation: strengthening of mathematics and science education in Western, East, Central, and Southern Africa (SUMASEWECSA) network. In: Kato $\mathrm{H}$ (ed) Scaling up south-south and triangular cooperation, pp 83-106. JICA Research Institute, Tokyo

Isoda M, Stephens M, Ohara Y, Miyakawa T (2007) Japanese lesson study in mathematics: its impact, diversity and potential for educational improvement. World Scientific Publishing, Singapore

JICA (Japan International Cooperation Agency) (2009) Study for roadside stations master plan. JICA, Tokyo

JICA (Japan International Cooperation Agency) (2013) Thematic guidelines for small and medium enterpris (SME) promotion. JICA, Tokyo

JICA (Japan International Cooperation Agency) (2015) JICA's world: education for all-expansion of opportunities and quality improvement. JICA, Tokyo

JICA (Japan International Cooperation Agency) (2016a) Kaizen: Japan's approach towards improved quality and productivity: the driving force of Japan's rapid growth. JICA, Tokyo

JICA (Japan International Cooperation Agency) (2016b) Corridor development approach. JICA, Tokyo

JICA (Japan International Cooperation Agency) (2019) JICA's initiatives in Africa: progress and achievements in activities for "investment for the future." JICA, Tokyo

JICA/JBIC (Japan International Cooperation Agency/Japan Bank for International Cooperation) (2008) Report of the stocktaking work on the economic development in Africa and the Asian Growth Experience. JICA/JBIC, Tokyo

Johnson S, Ostry JD, Subramanian A (2007) The prospect for sustained growth in Africa: benchmarking the constraints. NBER Working Paper. National Bureau of Economic Research, Cambridge

Kato H (2016) Japan's ODA 1954-2014: changes and continuities in a central instrument in Japan's foreign policy. In: Kato H, Page J, Shimomura Y (eds) Japan's development assistance: foreign aid and the post 2015 agenda. Palgrave Macmillan, New York, pp 1-18

Kato H, Hosono A (2013) Meeting the demand of the poor: two cases of business-led scaling up at the base of pyramid. In: Chandy L, Hosono A, Kharas H, Linn J (eds) Getting to scale: how to bring development solutions to millions of poor people. Brookings Institution, Washington, DC, pp 220-235

Kumakura M (2010) Interdependent relations and electronics industry in Asia Pacific economies. In: Akio W (ed) Asia Pacific and progress of new regionalism. Chikura Shobo, Tokyo

Kuznets S (1955) Economic growth and income inequality. Am Econ Rev 45(1):1-28

Lange G-M, Wodon Q, Carey K (2018) Changing wealth of nations 2018: building a sustainable future. World Bank, Washington, DC

Lin JY (2012) New structural economics: a framework for rethinking development and policy. World Bank, Washington, DC
Lin JY (2012) The quest for prosperity: how developing economies can take off. Princeton University Press, Princeton, NJ

MOFA (Ministry of Foreign Affairs, Japan) (2005) Japan's official development assistance 2005. MOFA, Tokyo

MOFA (Ministry of Foreign Affairs, Japan) (ed.). (2015). Quality infrastructure investment casebook. MOFA, Tokyo

Nishikata N (2017) Chubei no Kodomotachi ni Sansuu/Sugaku no Kojyo wo: Kyoukasho Kaihatsu wo Tsujita Kokusaikyouryoku 30 Nen no Kiseki [Improvement of mathematics for children in Central America: history of 30 years of international cooperation through textbook development]. JICA Research Institute, Tokyo

Noman A, Stiglitz JE (2012) Strategies for African development. In: Noman A, Botchwey K, Stein H, Stiglitz JE (eds) Good growth and governance in Africa: rethinking development strategies. Oxford University Press, Oxford, pp 3-47

Noman A, Stiglitz JE (2017) Learning, industrial, and technology policies: an overview. In: Noman A, Stiglitz JE (eds) Efficiency, finance, and varieties of industrial policy: guiding resources, learning, and technology for sustained growth. Columbia University Press, New York, pp 1-20

North D (1990) Institutions, institutional change and economic performance. Cambridge University Press, Cambridge

OECD (Organisation for Economic Co-operation and Development) and World Bank Group (2015) Inclusive global value chains: policy options in trade and complementary areas for GVC integration by small and medium enterprises and low-income developing countries. OECD, Paris

Page J, Shimeles A (2014) Aid, employment and poverty reduction in Africa. WIDER Working Paper 2014/043. UNU-WIDER, Helsinki

Seneviratne D, Sun Y (2013) Infrastructure and income distribution in ASEAN-5: what are the links. IMF Working Papers 13/41. International Monetary Fund, Washington, DC

Shibuya K (2013) Challenges in educational development in Africa and JICA's approach. In: For inclusive and dynamic development in Sub-Saharan Africa. JICA Research Institute, Tokyo, pp 267-298

Shimomura Y (2013) The Japanese view: with particular reference to the shared cognition model in Asia. In: Shimomura Y, Ohashi H (eds) A study on China's foreign aid: an asian perspective. Palgrave Macmillan, New York, pp 145-168

Shimomura Y (2016) The political economy of Japan's aid policy trajectory: with particular reference to the changes and continuity under the ODA charter. In: Kato H, Page J, Shimomura Y (eds) Japan's development assistance: foreign aid and the post 2015 agenda. Palgrave Macmillan, New York, pp 72-87

Stiglitz J, Greenwald B (2014) Creating a learning society: a new approach to growth, development, 
and social progress. Columbia University Press, New York

UNDP (UN Development Programme) (2008) Estudios de Casos: Red Local del Pacto Global Paraguay. UNDP, Asunción

UNDP (UN Development Programme) (2010) The MDGs: everyone's business: how inclusive business models contribute to development and who support them. UNDP, New York

UNDP (UN Development Programme)/Growing Inclusive Markets (2008) Creating value for all: strategies for doing business with the poor. UNDP, New York

UNECA (UN Economic Commission for Africa) (2013) Making the most of Africa's commodities: industrializing for growth, jobs and economic transformation. UNECA, Addis Ababa, Ethiopia

UNECLAC (UN Economic Commission for Latin America and the Caribbean) (1990) Changing production patterns with social equity: the prime task of Latin American and the Caribbean development in 1990s. UNECLAC, Santiago, Chile

UNECLAC (UN Economic Commission for Latin America and the Caribbean) (2012) Structural change for equality: an integrated approach to development. UNECLAC, Santiago, Chile

UNECLAC (UN Economic Commission for Latin America and the Caribbean) (2014) Regional integration: towards an inclusive value chain strategy. UNECLAC, Santiago, Chile

UNESCAP (UN Economic and Social Commission for Asia and Pacific) (2013) Shifting from quantity to quality: growth with equality, efficiency, sustainability and dynamism. UNESCAP, Bangkok

Open Access This chapter is licensed under the terms of the Creative Commons Attribution-NonCommercialNoDerivatives 4.0 International License (http:// creativecommons.org/licenses/by-nc-nd/4.0/), which permits any noncommercial use, sharing, distribution and reproduction in any medium or format, as long as you give appropriate credit to the original author(s) and the source, provide a link to the Creative Commons license and indicate if you modified the licensed material. You do not have permission under this license to share adapted material derived from this chapter or parts of it.
UNIDO (United Nations Industrial Development Organization) (2016) Industrial development report 2016: the role of technology and innovation in inclusive and sustainable industrial development. UNIDO, Vienna

United Nations (2015) Transforming our world: the 2030 agenda for sustainable development. https:// sustainabledevelopment.un.org/content/documents

UNU-WIDER (United Nations University World Institute for Development Economics Research) (2014) Aid, growth, and employment. UNU-WIDER, Helsinki

USAID (United States Agency for International Development) (2009) Sésamo: Innovación en Agronegocios. USAID, Asunción

Vinod T, Dailami M, Dhareshwar A, Kaufmann D, Kishor N, Lopez R, Wang Y (2000) The quality of growth. World Bank, Washington DC

World Bank (1993) East Asian miracle: economic growth and public policy. World Bank, Washington, DC

World Bank (2011) The changing wealth of nations: measuring sustainable development in the New Millennium. World Bank, Washington, DC

World Bank (2012) World development report 2013: jobs. World Bank, Washington, DC

World Bank (2019) World development report 2020: trading for development in the age of global value chains. World Bank, Washington, DC

Yamazawa I (1990) Flying wild geese pattern in pacific: pattern of industrial development among Asian countries. Distinguished Speakers Program, Asian Development Bank, Manila

Yokota T (2006) Guidelines for road side stations, "Michinoeki." World Bank, Washington DC

The images or other third party material in this chapter are included in the chapter's Creative Commons license, unless indicated otherwise in a credit line to the material. If material is not included in the chapter's Creative Commons license and your intended use is not permitted by statutory regulation or exceeds the permitted use, you will need to obtain permission directly from the copyright holder. 